REVIEW

\title{
The car seat: a challenge too far for preterm infants?
}

\author{
E Pilley, W McGuire
}

Arch Dis Child Fetal Neonatal Ed 2005;90:F452-F455. doi: 10.1136/adc.2004.064295

Physiological monitoring studies have shown that some preterm infants who are otherwise ready for hospital discharge experience episodes of oxygen desaturation, apnoea, or bradycardia when seated in standard car safety seats. The American Academy of Pediatrics recommends that all preterm infants are assessed for cardiorespiratory stability in their car seat before discharge: the "car seat challenge". This screening test has been incorporated into discharge assessments in most neonatal units in North America and is being increasingly used in the United Kingdom and elsewhere. The evidence base for the use of the car seat challenge in discharge assessment, the possible implications for infants, their families, and health services of adopting the practice, and the issues that may be resolved with further research are discussed.

See end of article for authors' affiliations

Correspondence to Dr McGuire, Tayside Institute of Child Health, Ninewells Hospital and Medical School, Dundee DDI 9SY, Scotland, UK; w.mcguire@dundee.ac.uk

Accepted

26 February 2005
$\mathrm{P}$ reterm infants are typically discharged from hospital when they reach a postconceptional age of about 35-37 weeks. At this stage, most infants are growth restricted, typically weighing less than $2.5 \mathrm{~kg}$. ${ }^{1}$ Some infants have a ity at discharge. A minority has more significant problems-for example, chronic lung disease needing supplemental oxygen therapy.

The recommended mode of carriage for neonates and young infants travelling by car after hospital discharge is in the semi-upright position in a rear facing safety seat with a three or five point harness (fig 1). Infants and young children who are involved in collisions as car passengers are less likely to die or be seriously injured if they are restrained in a car seat appropriate for their size. ${ }^{2}$ However, car safety seats are designed for the "average" term newborn infant. Careful attention to correct positioning is essential to provide smaller infants with optimal restraint Academy of Pediatrics have made the following recommendations for positioning preterm infants in car safety seats. ${ }^{3-5}$

- Use infant-only, rear facing car safety seats with three or five point harness systems

- The car safety seat should be semi-reclined (to a $45^{\circ}$ angle) in the rear seat of the car, ideally adjacent to an adult

- Place the infant's buttocks and back firmly against the back of the car safety seat (reduces slouching)

- The distance from the crotch strap to the seat back should be $\leqslant 14 \mathrm{~cm}$ and from the lower degree of respiratory and neurological immaturand protection from impact. The American harness strap to the seat bottom should be $\leqslant 25 \mathrm{~cm}$

- Shoulder straps should be in the lowest slots until the infant's shoulders are above the slots

- Place the retainer clip over the midpoint of the chest rather than on the abdomen or near the neck

- The car safety seat should not be placed in the front passenger seat of a car with a passenger side front air bag

- The infant should not be left unattended in a car safety seat

There is also concern that preterm infants may be prone to respiratory compromise when carried in seats that are intended for larger babies. Studies undertaken in the United States in the 1980s first highlighted the problems that preterm infants may face when using standard infant car safety seats. ${ }^{6-8}$ Bull and Stroup ${ }^{6}$ found that a range of standard car safety seats provided suboptimal postural support for infants weighing about $2 \mathrm{~kg}$ because the strap distances from the seat bottom to the lowest shoulder strap and seat back to crotch strap were too long. Willett and colleagues $^{78}$ hypothesised that the tendency for infants carried in these seats to slouch would compromise respiration. In physiological monitoring studies, these investigators found that $30-60 \%$ of preterm infants who were otherwise ready for hospital discharge (average weight when studied $2.3 \mathrm{~kg}$ ) had frequent episodes of hypoxia (oxygen saturation less than $85 \%$ ) during a 90 minute observation period. The incidence of hypoxia was inversely related to birth weight and gestational age at birth. Preterm infants who had a previous history of apnoea were more prone to have episodes of apnoea and bradycardia. Randomly selected term infants (average weight $3.4 \mathrm{~kg}$ ) did not become hypoxic or bradycardic during the same test period. Possible mechanisms of respiratory compromise in preterm infants in car seats are $\mathrm{a}^{9-11}$ :

- Slouching causes neck flexion and impingement of the tongue on the posterior pharyngeal wall

- The prominent occiput of the neonate accentuates the tendency to neck flexion

- Immaturity of the head righting reflex and weak neck muscles prevents correction

- Posterior displacement of mandible compresses the middle airway space

\section{THE "CAR SEAT CHALLENGE"}

Largely because of these findings, the American Academy of Pediatrics recommended in 1991 


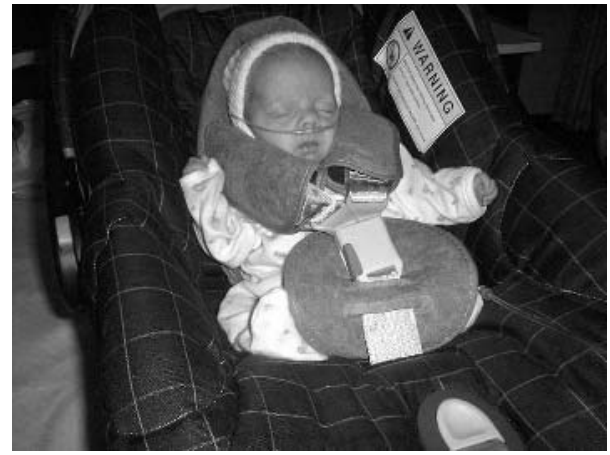

Figure 1 Preterm infant in the recommended semi-upright position in a rear facing safety seat with a three point harness. Permission for the publication of this figure has been obtained.

(updated 1996, 1999) that after hospital discharge preterm infants should not be left unsupervised in a car safety seat and that car safety seats "should be used only for travel, and that travel should be minimized during the first months of life $^{\prime \prime} .^{3-5}$ They also recommended that preterm infants should be observed and monitored for apnoea, bradycardia, or oxygen desaturation in their car safety seat before hospital discharge: the car seat challenge. The guidelines advised that infants who experienced episodes of apnoea for more than 20 seconds, bradycardia (less than 80 beats/min), or oxygen desaturation (less than 90\%) should not travel in the car safety seat.

In the United States, the car seat challenge is recommended not only for those preterm infants who have had respiratory problems but also for infants born near term at 35-36 weeks gestation. Most of these infants are likely to have had no respiratory problems. In support of this very broad inclusion criterion, Merchant and colleagues ${ }^{12}$ have reported that about one quarter of near term infants did not fit securely into standard car safety seats despite the use of blanket rolls. One in eight healthy near term infants had apnoeic or bradycardic events in their car seats.

Most level II and level III neonatal units in United States have incorporated car seat challenges into their routine discharge assessment for preterm infants. However, there is wide variation between units in the way that the test is used..$^{13}$ Neonatal units differ in their indications for testing, the duration of observation and monitoring, and the criteria for "passing" the test. Evidence exists that neonatal unit to unit variation in the timing of hospital discharge for healthy preterm infants may be partly explained by differences in criteria for determining cardiorespiratory stability while in a car seat. ${ }^{14} 15$

There is also considerable variation in the recommendations given to parents of infants who "fail" the car seat challenge. ${ }^{13}$ The alternatives include:

1. Delaying hospital discharge until the infant "passes" the test, usually within one week. ${ }^{16}$ Infants may pass the test then because they are bigger and more mature. Test to test variability may also play a role.

2. Modifying the seat with blanket rolls or inserts to provide sufficient postural support for the infant to pass the test. Slouching may be reduced by placing the infant's buttocks and back firmly against the back of the car seat and by placing a blanket roll between the crotch strap and the infant. Additional blanket rolls may be required on both sides of the head and neck to provide support in the event of lateral movement. Various car seat inserts are now commercially available. Tonkin and colleagues $^{17}$ in New Zealand have designed an $\mathrm{H}$ shaped car seat insert that allows the baby's head to rest in a neutral position preventing forward flexion (fig 2). This insert reduces the frequency of episodes of desaturation. Prevention of lateral slouching only through the use of a specially designed head support is less effective in preventing respiratory compromise in preterm infants in car seats. ${ }^{18}$

3. The infant travels in a more supine position. Positioning the safety seat at about $30^{\circ}$ rather than $45^{\circ}$ may reduce slouching and respiratory obstruction. ${ }^{19}$ Car seat inserts can be placed behind the infant's lower back to move the infant to a more reclined position in the seat. However, it is not clear whether this position provides optimal restraint in the event of a collision. Similarly, transporting the infant in a fully supine or prone position in a carrycot with restraint straps is possible, but carrycots are not designed to withstand the forces generated in a collision. Although recumbent car beds and seats that are as effective as conventional car seats in limiting collision impact have been developed recently, availability and cost has limited their use.

4. The infant is given a respiratory stimulant such as theophylline. This intervention has been used on the premise that treating apnoea of prematurity (which may persist beyond term) improves the infant's cardiorespiratory stability in the car seat. There is little robust evidence that this is the case, although there are case reports of infants who have had fewer episodes of apnoea or bradycardia after theophylline treatment. ${ }^{16}$

\section{A CHALLENGE TOO FAR?}

The car seat challenge has been introduced on the assumption that the test will identify infants who are at risk of avoidable adverse events while in a car safety seat. However, it is also important to consider whether there are other possible consequences of the use of the car seat challenge in hospital discharge assessments for infants, their families, and health services. ${ }^{20}$ Several key issues are unresolved.

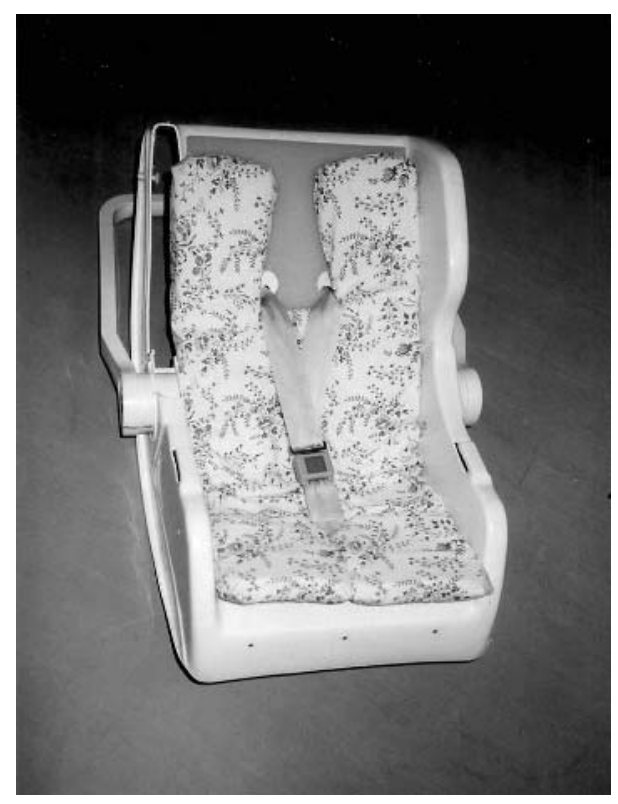

Figure $2 \mathrm{H}$ shaped car seat insert that allows the baby's head to rest in a neutral position preventing forward flexion. Permission for publication of this figure has been obtained. 


\section{Test validity}

There are limited data on the test to test variability of the car seat challenge. Several factors may be expected to affect the results of the test-for example, the infant's feeding and sleeping pattern. Apnoeic pauses occurring during active sleep are more likely to be associated with oxygen desaturation, especially in preterm infants. ${ }^{21}$ Infants awake at the time of testing may therefore be more likely to "pass". Further studies are needed to define the extent of test to test variability and to clarify the relation of sleep and feeding to episodes of desaturation.

\section{Clinical significance of desaturation}

There is little evidence that the degree and duration of episodes of desaturation, bradycardia, or apnoea that are seen in preterm infants who "fail" the car seat challenge is of clinical importance. Preterm infants who are otherwise ready for discharge commonly have self limiting episodes of obstructive apnoea when not in car seats (often related to feeding), but the existing data indicate that the severity of these episodes is not related to the risk of acute life threatening events in early infancy. ${ }^{22-24}$ Although a review article has cited anecdotal reports of apparent life threatening events and sudden and unexpected deaths in preterm and term infants while semi-reclined in car safety seats, ${ }^{25}$ we have not found any primary reports in a systematic search of the literature:

- Electronic searches of Medline (1966-June 2005), Embase (1980-June 2005), and Cinahl (1982-June 2005) using these MeSH terms and text words: Infant, Newborn OR Infant, Premature OR Infant, Low Birth Weight, OR Infant, Very Low Birth Weight AND Infant Equipment/ OR car seat challenge (no language restriction)

- Hand searches of references in previous reviews and studies identified as potentially relevant

- Hand searches of abstracts presented at the annual scientific meetings of the Society for Pediatric Research, the European Society for Pediatric Research from 1990 until 2004

A more reliable estimate of the frequency of major adverse events in infants in car seats may be available through collation of national data reporting sudden and unexpected infant deaths, or through national prospective surveillance schemes that can ascertain all suspected cases.

It may be much more difficult to determine whether intermittent apnoea and desaturation in early infancy is associated with adverse longer term neurodevelopmental outcomes. Cohort studies of infants with chronic hypoxia, usually due to cyanotic heart disease, have suggested that infants who had a longer duration of hypoxia had more cognitive impairment. ${ }^{26}$ However, these findings should probably not be directly extrapolated to infants with episodic brief desaturations.

The least biased assessment of whether the use of the car seat challenge affects clinically important outcomes, including infant mortality, apparently life threatening events, need for hospital admission, and long term neurodevelopment, would require a very large randomised controlled trial. Such a trial may be difficult to undertake in countries such as the United States where the use of the car seat challenge is already widely used and where there may be medicolegal consequences of not complying with national guidelines. It is important to determine whether equipoise still exists in other countries and whether such a trial would be supported by parents and carers. This may not be the case. Even in the absence of a national guideline in the United Kingdom, a recent survey of practice in Scotland indicated that almost half of all neonatal units already used a car seat challenge in discharge assessment of at least some preterm infants (E Pilley, unpublished).

\section{"Labelling"}

In common with other screening procedures, it is necessary to consider the effect of using the car seat challenge on all of the infants and families who are tested. For those infants who "fail", does this unduly increase parental concern about their infant's general health? Even for those infants who "pass" but still have some episodes of desaturation or bradycardia while in the car seat, does this completely reassure parents that their child is not at risk of adverse events in the car seat (or in a carry sling or high chair)? It would be concerning if parents chose on the basis of a car seat challenge result to carry their infants in their arms but otherwise unsecured while travelling in a car. Qualitative research exploring parental perceptions and concerns may help to determine whether the car seat challenge alleviates or increases parental anxiety and may aid in identifying potential consequences of this.

\section{Costs}

The use of the car seat challenge in discharge assessments of all preterm infants has cost implications for health services and families. Undertaking cardiorespiratory monitoring for 90 minutes for all preterm infants will occupy a substantial proportion of nursing time. Delaying hospital discharge for the infants who "fail" the test could have major effects on cot occupancy and availability in neonatal units. This may have downstream consequences on intensive care availability resulting in more interhospital or inter-region transfers of preterm or unwell infants.

\section{CONCLUSION}

It is reasonable practice to assist parents at the time of hospital discharge with the correct use of their car safety seat and to advise that infants should not be left unsupervised or unnecessarily long in the car seat. However, it should be explained to families that apparent cardiorespiratory abnormalities in infants who were born before term are common at the time of hospital discharge and do not predict an increased risk of sudden and unexpected death in infancy. The currently available data are insufficient to determine whether undertaking a car seat challenge improves clinically important outcomes for preterm infants. Further research to evaluate the validity and utility of the test is needed.

\section{ACKNOWLEDGEMENTS}

We thank Dr Shirley Tonkin for permission to use the picture of the car seat insert (fig 2).

\section{Authors' affiliations \\ E Pilley, Gartnaval General Hospital, Glasgow G12 OYN, Scotland, UK W McGuire, Tayside Institute of Child Health, Ninewells Hospital and Medical School, Dundee DDI 9SY, Scotland, UK \\ Competing interests: none declared \\ Permission for the publication of figs 1 and 2 has been obtained. \\ REFERENCES \\ 1 Clark RH, Thomas P, Peabody J. Extrauterine growth restriction remains a serious problem in prematurely born neonates. Pediatrics 2003;111:986-90. \\ 2 Scherz RG. Restraint systems for the prevention of injury to children in automobile accidents. Am J Public Health 1976;66:451-6. \\ 3 Committee on Injury and Poison Prevention and Committee on Fetus and Newborn, American Academy of Pediatrics. Safe transportation of premature infants. Pediatrics 1991;87:120-2. \\ 4 Committee on Injury and Poison Prevention and Committee on Fetus and Newborn, American Academy of Pediatrics. Safe transportation of premature and low birth weight infants. Pediatrics 1996;97:758-60.}


5 Bull M, Agran P, Laraque D, et al. American Academy of Pediatrics. Committee on Injury and Poison Prevention. Safe transportation of newborns at hospital discharge. Pediatrics 1999:104:986-7.

6 Bull MJ, Stroup KB. Premature infants in car seats. Pediatrics 1985;75:336-9.

7 Willett LD, Leuschen P, Nelson LS, et al. Risk of hypoventilation in premature infants in car seats. J Pediatr 1986;109:245-8.

8 Willett LD, Leuschen P, Nelson LS. Ventilatory changes in convalescent infants positioned in car seats. J Pediatr 1989:15:451-5.

9 Stark AR, Thach BT. Mechanisms of airway obstruction leading to apnoea in newborn infants. J Pediatr 1976;89:982-984.

10 Thach BT, Stark AR. Spontaneous neck flexion and airway obstruction during apnoeic spells in preterm infants. J Pediatr 1979;94:275-81.

11 Reed WR, Roberts JL, Thach BT. Factors influencing regional patency and configuration of the human infant upper airway. J Appl Physiol 1985;58:635-44.

12 Merchant JR, Worwa C, Porter S, et al. Respiratory instability of term and near-term healthy newborn infants in car safety seats. Pediatrics $2001 ; 108: 647-52$

13 Williams LE, Martin JE. Car seat challenges: where are we in implementation of these programs? J Perinat Neonatal Nurs 2003;17:158-63.

14 Eichenwald EC, Blackwell M, Lloyd JS, et al. Inter-neonatal intensive care unit variation in discharge timing: influence of apnea and feeding management. Pediatrics 2001;108:928-33.

15 Merritt TA, Pillers D, Prows SL. Early NICU discharge of very low birth weight infants: a critical review and analysis. Semin Neonatol 2003;8:95-115.
16 Young B, Shapira S, Finer NN. Predischarge car seat safety study for premature infants. Paediatr Child Health 1996;1:202-5.

17 Tonkin SL, Mclntosh CG, Hadden W, et al. Simple car seat insert to prevent upper airway narrowing in preterm infants: a pilot study. Pediatrics 2003;112:907-13.

18 Dollberg S, Yacov G, Mimouni F, et al. Effect of head support on oxygen saturation in preterm infants restrained in a car seat. Am J Perinatol 2002;19:115-18

19 Smith PS. The physiologic effects of positioning premature infants in car seats. Neonatal Netw 1990;9:11-15.

20 Stein N. Car-seat test. Pediatrics 2004;113:1469.

21 Stark AR, Cohlan BA, Waggener TB, et al. Regulation of end-expiratory lung volume during sleep in premature infants. J Appl Physiol 1987;62:1117-23.

22 Barrington KJ, Finer N, Li D. Pre discharge respiratory recordings in very low birth weight newborn infants. J Pediatr 1996;129:934-40.

23 Eichenwald EC, Aina A, Stark AR. Apnea frequently persists beyond term gestation in infants delivered at 24 to 28 weeks. Pediatrics 1997; 100:354-9.

24 Cote A, Hum C, Brouillette RT, et al. Frequency and timing of recurrent events in infants using home cardiorespiratory monitors. J Pediatr 1998;132:783-9.

25 Bass JL, Bull M. Oxygen desaturation in term infants in car safety seats [commentary]. Pediatrics 2002;110:401-2.

26 Bass JL, Corwin M, Gozal D, et al. The effect of chronic or intermittent hypoxia on cognition in childhood: a review of the evidence. Pediatrics $2004 ; 114: 805-16$. 